\title{
Choice of parents for developing two line hybrids in rice (Oryza sativa $L$.)
}

\author{
V. Karpagam* ${ }^{1}$ and R. Kalaiyarasi ${ }^{2}$ \\ ${ }^{1}$ Department of Plant Breeding and Genetics, Vanavarayar Institute of Agriculture, Pollachi - 642103 (Tamil \\ Nadu), INDIA \\ ${ }^{2}$ Centre for Plant Breeding and Genetics, Tamil Nadu Agricultural University, Coimbatore - 641003 (Tamil Nadu), \\ INDIA \\ *Corresponding author. Email: priyatnau2007@yahoo.co.in
}

Received: December 2, 2016; Revised received: May 4, 2017; Accepted: September 20, 2017

\begin{abstract}
An investigation was carried out to evaluate two line hybrids in rice for yield traits. Four TGMS lines and eleven testers were crossed in line $\mathrm{x}$ Tester design. Greater proportion of sca variance was observed for all the characters which revealed that preponderance of non- additive gene action governing traits concerned and selection procedures based on the accumulation of additive effects would be successful in improving these traits. The line TS09 24 and testers viz., T 2006, KDML 105, Improved white ponni and BPT 5204 were found to be good combiners for the yield and yield components. The best hybrids based on sca value, TNAU 27S x Improved white ponni was derived from low $x$ low combiners for thousand grain weight and TS 29 X ADT 38 for the number of filled grains per panicle spikelet fertility. The best performing hybrid TS 29 x KDML 105 produced $54.25 \mathrm{~g}$ of grain yield per plant in 128 days which was 92.89 and 85.47 per cent increase over the standard checks CORH 3 and Improved white ponni respectively. This hybrid also recorded 27.32 and 64.30 per cent increase CORH 3 and Improved white ponni for thousand grain weight. Hence, the two line hybrid breeding system, utilizing thermo sensitive genic male sterility is economically feasible as well as viable alternative to cytoplasmic male sterile (CMS) based three line breeding due to much simplified hybrid seed production.
\end{abstract}

Keywords: Coryza sativa, TGM lines, Two line hybrids, SCA variance, Seed production

\section{INTRODUCTION}

Hybrid rice technology is the most promising approach to break yield barriers in rice, being practically feasible and readily exploitable. As rice is a self-pollinated species, use of male sterility is essential for hybrid rice breeding and seed production (Stephen et al., 2016). To cope up with the ever increasing demand for rice it should be met with quantum jump in production in fixed cultivable area. This is a daunting task, in view of plateauing trend observed in yield potential of high yielding varieties declining natural resource base (Gopikannan and Ganesh, 2013).

The discovery and application of thermo sensitive genic male sterility has great potential for revolutionizing hybrid seed production technology in rice. In the tropics TGMS is more practical to use since day length difference is marginal (Virmani and Ilyas, 2001 and Dhivyapriya et al., 2015). Male sterility in temperature sensitive genic male sterile (TGMS) lines is heritable. Higher temperature $\left(>30^{\circ} \mathrm{C}\right)$ results in sterility while lower temperature $\left(<23{ }^{\circ} \mathrm{C}\right)$ results in fertility. (Yuan, 1990 and Arasakesary et al., 2015).

The main advantages of two line heterosis breeding include the ability to use a wide range of genotypes as male parents, absence of negative effects associated with sterility-inducing cytoplasm and no need for maintainer lines. These two line hybrids have 5-10 per cent yield advantage over the three line hybrids (Arasakesary et al., 2015). Line $\mathrm{x}$ Tester analysis is a powerful tool to discriminate the good as well as poor combiners for choosing appropriate parental material in successful hybrid breeding programme. However, the success of hybrid rice programme depends upon the magnitude of heterosis which also helps in the identification of potential cross combinations to be used in the conventional breeding program to create wide array of variability in the segregating generations (Akter et al., 2010). The present investigation was carried out to study the combining ability in order to identify good combiners and superior hybrid combinations.

\section{MATERIALS AND METHODS}

Four TGMS lines and eleven testers were crossed in line $\mathrm{x}$ Tester design. The lines used for the experiments were TNAU 27S, TS09 24, TS09 26 and TS 29. Eleven testers viz. $\mathrm{CO}(\mathrm{R})$ 49, ADT 38, Improved white ponni (IWP), BPT 5204, KDML 105, WGL 14, G 14, T 2006, T 972, T 360 and CB $87 \mathrm{R}$ and the CORH 3 and Improved white ponni were used as the standard checks. An investigation was carried out at 
Paddy Breeding Station, Centre for Plant Breeding and Genetics, Tamil Nadu Agricultural University, Coimbatore with the objective of developing two line hybrids in rice using Thermo sensitive genic sterility (TGMS) lines system and estimating the extent of heterosis in these hybrids. The four TGMS lines and eleven testers were raised in a crossing block for hybridization. Three staggered sowing of parental lines were taken up at 15 days interval for the synchronization of flowering. Crossing was done in line $\mathrm{x}$ tester mating design. During the hybridization period, the TGMS lines were sterile under high temperature regime, when the maximum and minimum temperature was $36.2^{\circ} \mathrm{C}$ and $26.2^{\circ} \mathrm{C}$ respectively. Based on the microscopic studies of the anthers 100 per cent sterile plants were identified and labelled. The spikelets of the unopened panicles were cut to one third of its length and the TGMS lines being male sterile, are not emasculated. They were bagged with butter paper cover to avoid contamination. This process was done at the beginning of anthesis time (7.00 A.M. to 9.00 A.M). During the time of anthesis (10.00 A.M. to 11.30 A.M.), partially opened panicles were selected from the testers (pollinators) and were churned over the panicles of the lines that were bagged earlier so that the pollen grains were dusted on it. The crossed panicles were covered and labelled. Twenty five days after pollination, the crossed seeds were collected and adequately dried.

Hybridization and production of $\mathbf{F}_{1:}$ The fourty four hybrids and fifteen parents were raised during 2011 at Kharif season in randomized block design with two replications by adopting a spacing of $20 \times 15 \mathrm{~cm}$ accommodating ten plants per replication. Single seedling per hill was planted.

Biometric observations in $F_{1} s$ and parents: At flowering, in each replication five competitive plants in the middle of rows were selected in each treatment at random and tag labeled. Nine biometrical observations viz., days to fifty per cent flowering, plant height, number of productive tillers per plant, panicle length, number of grains per panicle, number of filled grains per panicle, spikelet fertility, thousand grain weight and grain yield per plant were recorded at the time of maturity on all tagged plants. The mean values recorded for nine characters in the parents and $F_{1}$ generations were used for statistical analysis. The analysis was done using the INDOSTAT statistical package (INDOSTAT services, Hyderabad). Analysis of variance of four lines, eleven testers and fourty four hybrids were carried out forthe quantitative characters following the procedure outlined by Panse and Sukhatme (1964). The combining ability analysis was done by using Line $\mathrm{x}$ Tester mating design as described by Kempthorne (1957). The performance of F1 hybrids was evaluated on the basis of heterosis estimates (Fonseca and Patterson, 1968). Significance of heterosis was tested using the formula given by Snedecor and
Cochran (1967).

\section{RESULTS AND DISCUSSION}

Analysis of variance: In the estimate of variances, the mean squares due to lines, testers, hybrids, line $\mathrm{x}$ tester in interactions and general and specific combining ability variances are presented in Table 1. The lines and the testers showed higher positively significant differences for all the characters studied. In genetic analysis, it is presumed that $g c a$ and $s c a$ reflect additive gene action and the non additive gene action respectively. In the present study, greater proportion of $s c a$ variance was observed for all the characters which revealed that preponderance of non- additive gene action governing the traits concerned and selection procedures based on the accumulation of additive effects would be successful in improving these traits. This is in accordance with findings of Utharasu and Anandakumar (2013) for days to fifty per cent flowering, plant height, number of productive tillers per plant, panicle length, number of grains per panicle, spikelet fertility, hundred grain weight and grain yield per plant. Dhivyapriya and Kalaiyarasi (2014) recorded higher sca for the characters viz., days to fifty per cent flowering, plant height, number of productive tillers per plant, panicle length, number of grains per panicle, number of filled grains per panicle, spikelet fertility, thousand grain weight and grain yield per plant and Sasikala et al. (2015) for days to fifty per cent flowering, plant height, number of productive tillers, panicle length, number of spikelets per panicle, number of filled spikelets per panicle, spikelet fertility percentage, 1000 grain weight and single plant yield.

Per se performance: The mean performances of parents are presented in Table 2. High mean value remains as the main selection index in the choice of parents. Gilbert (1958) pointed out that the parents with high per se performance will result in superior hybrids. Among the lines, TNAU 27S exhibited significantly high per se performance for maximum six characters viz., plant height (negative direction), number of productive tillers, panicle length, spikelet fertility, thousand grain weight and the grain yield per plant. Among the testers, T 972 exhibited high per se performance for the characters viz., days to fifty per cent flowering (negative direction), spikelet fertility and thousand grain weight. Hence these parents can be utilized in hybrid breeding programmes. The general and specific combining ability effects of the parents and the hybrids are presented in the Tables 3 and 4.

gca effects: Dhillion (1975) pointed out that combining ability of parents gives useful information on the choice of parents in terms of expected performance of their progenies in maize. Among the lines TS09 24 was found to be good combiner for the panicle length, number of grains per panicle, number of filled grains 
V. Karpagam and R. Kalaiyarasi / J. Appl. \& Nat. Sci. 9 (4): 2047 - 2054 (2017)

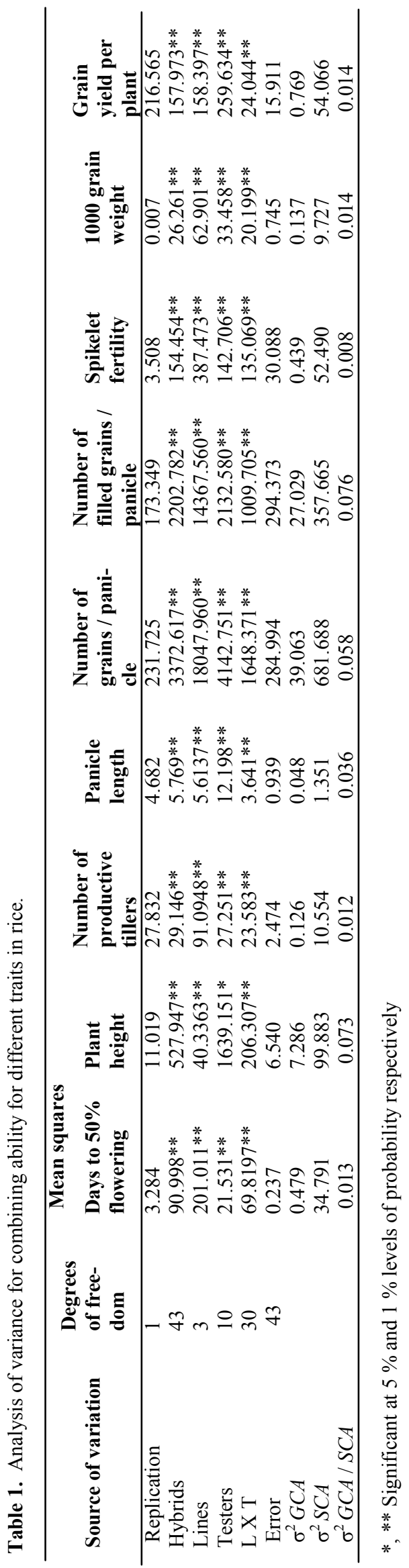

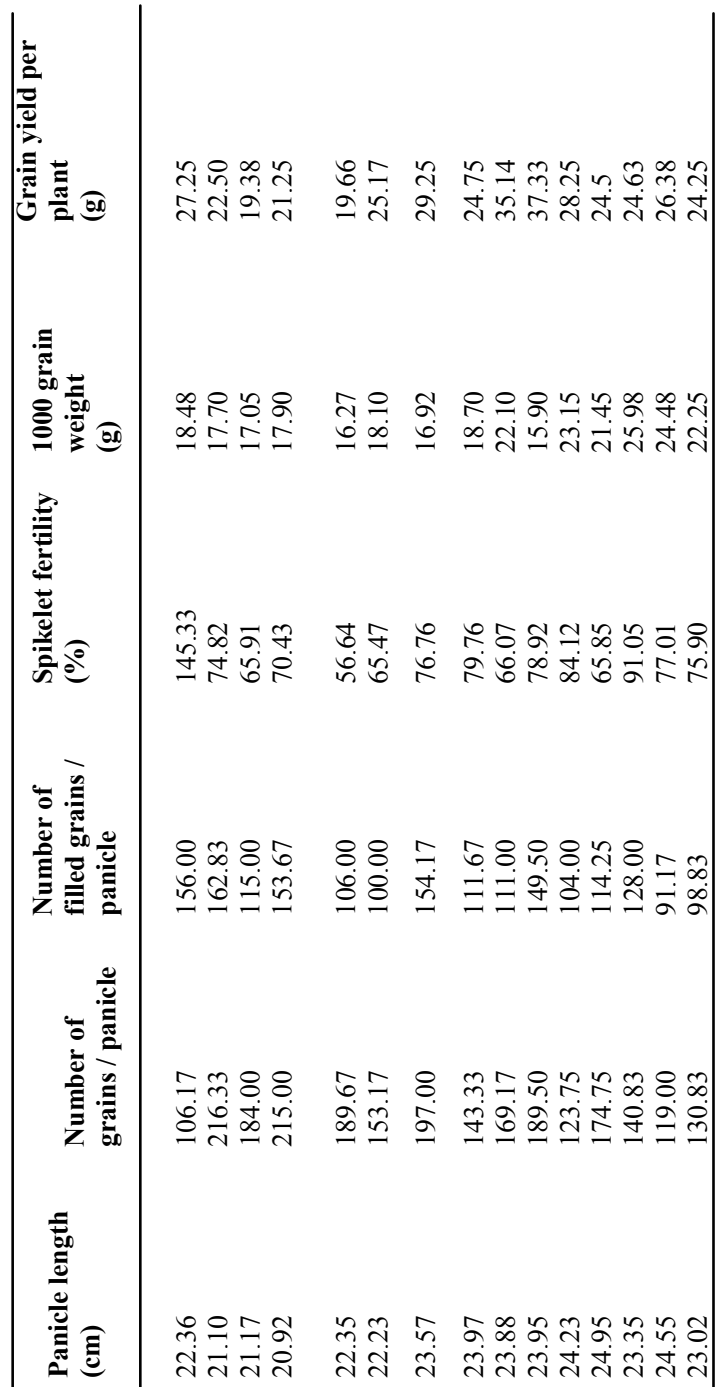

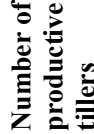

\&:n

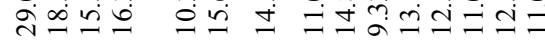

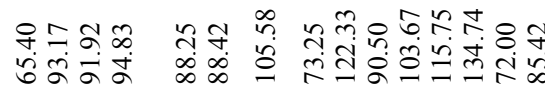

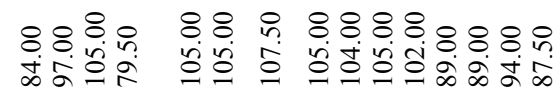




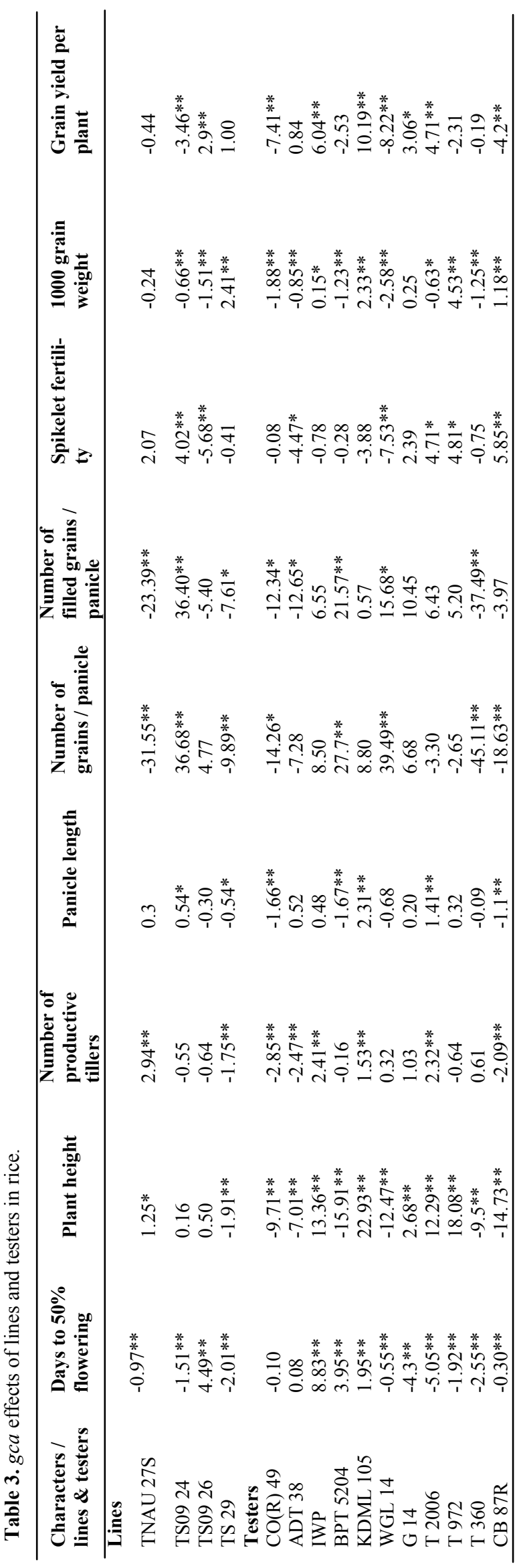

per panicle and the spikelet fertility, while TNAU 27S showed gca effects for productive tillers and days to fifty per cent flowering. The line TS 29 showed higher negatively significant $g c a$ effect for days to fifty per cent flowering and higher positive significant for thousand grain weight. Among the testers, T 2006 was the good combiners for the number of productive tillers per plant, panicle length, spikelet fertility, grain yield per plant and (negative direction); KDML 105 for the characters panicle length, and the grain yield per plant; BPT 5204 for the number of grains per panicle, number of the filled grains per panicle and plant height (negative direction); $\mathrm{CB} 87 \mathrm{R}$ for the plant height (negative direction) and days to fifty per cent flowering. The tester Improved white ponni was the good combiner for the number of productive tillers, thousand grain weight and grain yield per plant. The $g c a$ effect is generally associated with additive gene action in the inheritance of a particular character.

Hence line TS09 24 and testers viz., T 2006, KDML 105, Improved white ponni and BPT 5204 were found to be good general combiners for the yield and yield components and also can be used as potential donors for improvement of yield potential or yield with early maturity in rice as suggested by Singh et al. (2013), Dhivyapriya and Kalaiyarasi (2014) and Sasikala et al. (2015).

sca effects: The $s c a$ effect is an index to determine the usefulness of a particular cross combination (Peng and Virmani, 1990). Among the hybrids, TNAU 27S x KDML 105 showed higher sca effects for days to fifty per cent flowering, number of productive tillers and panicle length. The hybrid, TNAU 27S x Improved white ponni had shown highly positive significant $s c a$ effects for three characters viz., panicle length, spikelet fertility and grain yield per plant. The hybrid, TS09 24 x T 2006 had higher negative $s c a$ effects for days to fifty per cent flowering and had higher positive $s c a$ effects for number of productive tillers; TS $29 \times$ BPT 5204 for the number of grains per panicle and number of filled grains per panicle; TS09 24 x Improved white ponni reported highly positive significant for the spikelet fertility and the grain yield per plant. Hence these hybrids were found to have specific combiners for most of the yield and yield component traits.

The hybrids viz., TNAU $27 \mathrm{~S} \times$ Improved white ponni, TNAU 27S x T 2006 and TS09 26 x CB 87R involved low $\mathrm{x}$ high combiners and this may be due to interaction between dominant alleles from the good combiner and recessive alleles from the poor combiners (Hasan et al. 2013). The hybrid, TS09 $26 \times$ T2006 involved both the parents, which were good combiners. This would involve interaction between positive $\mathrm{x}$ positive alleles and are fixable in subsequent generation in rice. Kalitha and Upadhaya (2000), Shivani et al. (2009) and Salgotra et al. (2009) also reported about interaction between positive and positive alleles in crosses 
V. Karpagam and R. Kalaiyarasi / J. Appl. \& Nat. Sci. 9 (4): 2047 - 2054 (2017)

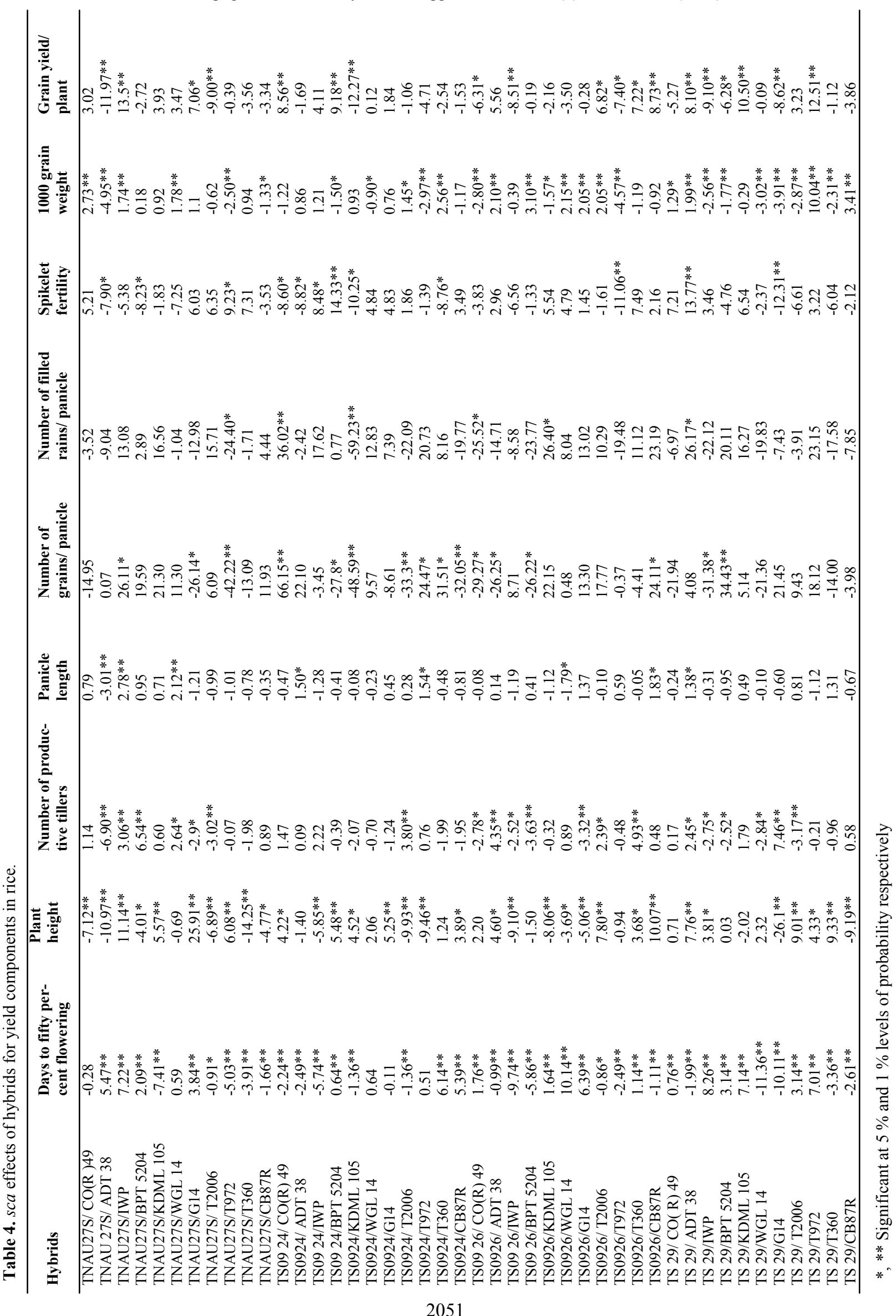




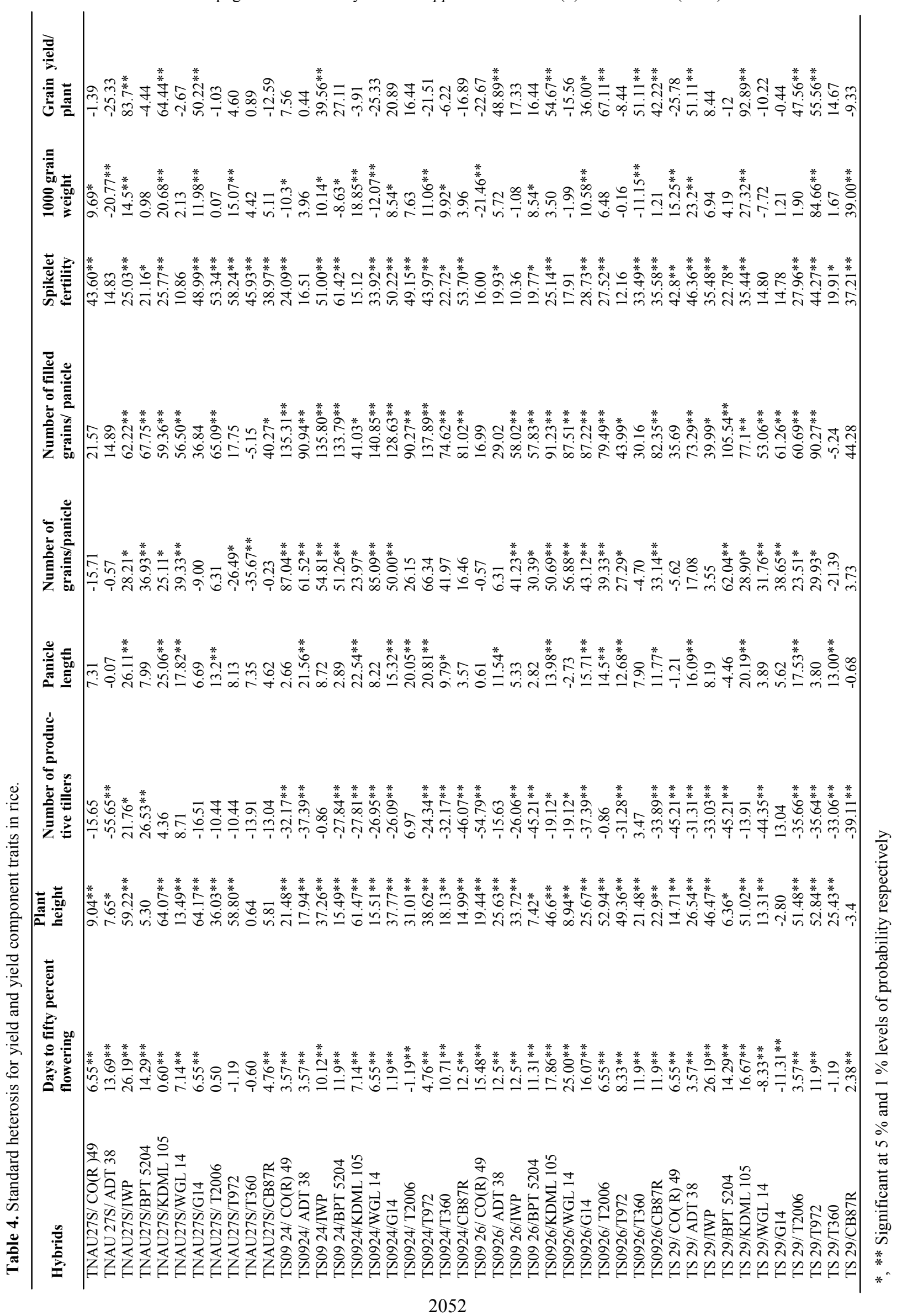


involving high $\times$ high combiners which can be fixed in subsequent generations if no repulsion phase linkages are involved. In other hybrids, the parental combinations had either medium $\mathrm{x}$ medium or low $\mathrm{x}$ medium gca effects indicating a complementary gene action leading to superior $\mathrm{F}_{1}$ hybrids.

The best hybrids based on sca value, TNAU $27 \mathrm{~S} \times$ Improved white ponni was derived from low $\mathrm{x}$ low combiners for thousand grain weight and TS $29 \mathrm{X}$ ADT 38 for the number of filled grains per panicle spikelet fertility. This may be due to the non-additive gene action such as epitasis (Hasan et al., 2013). Therefore no relationship could be established between $g c a$ effects of parents and $s c a$ effects of hybrids since some minor gene effects may also deviate the expected results. These cross combinations can be used for exploitation of heterosis in further hybrid breeding programme.

Heterotic vigour of hybrids: The estimates of heterosis based on standard checks are given in Table 5 . Negative heterosis for days to fifty per cent flowering and plant height is a desirable trait as it confers earliness and resistance to lodging respectively. TNAU $27 \mathrm{~S}$ $\mathrm{x}$ Improved white ponni recorded highly positive heterosis for grain yield per plant, number of grains per panicle, panicle length, number of filled grains per panicle, thousand grain weight, days to fifty per cent flowering (negative direction), plant height (negative direction) and spikelet fertility. The hybrid, TS $29 \mathrm{x}$ KDML 105 showed highly negative significant standard heterosis for plant height and days to fifty per cent flowering and highly positive significant heterosis for grain yield per plant, number of grains per panicle, thousand grain weight, panicle length, spikelet fertility, and number of filled grains per panicle; The crosscombination,TS09 26 × T 2006 had shown higher positive standard heterosis for grain yield per plant, number of grains per panicle, panicle length, plant height, number of filled grains per panicle, spikelet fertility and days to fifty per cent flowering (negative heterosis); TNAU 27S x KDML 105 had exhibited highly positive significant heterosis for for grain yield per plant, number of grains per panicle, plant height, panicle length, spikelet fertility, days to fifty per cent flowering (negative heterosis), number of filled grains per panicle and thousand grain weight. Hence, the above said hybrids are highly suitable for commercial exploitation of heterosis. This is in accordance with findings of Dhivyapriya and Kalaiyarasi (2014) for days to 50 percent flowering (negative heterosis), plant height (negative heteosis), number of productive tillers, number of grains per panicle and thousand grain weight and Sasikala et al. (2015) for to 50 percent flowering (negative heterosis), number of spikelets per panicle, number of filled spikelets per panicle and thousand grain weight.

\section{Conclusion}

The best performing hybrid TS 29 X KDML 105 produced $54.25 \mathrm{~g}$ of grain yield per plant in 128 days which was 92.89 and 85.47 per cent increase over the standard checks CORH 3 and Improved white ponni respectively. This hybrid also recorded 27.32 and 64.30 per cent increase CORH 3 and Improved white ponni for thousand grain weight. This was followed by TNAU 27S X Improved white ponni, TS09 26 X T 2006 and TNAU 27S X KDML105. These hybrids can be utilized for commercial exploitation since they recorded at least 10 per cent more grain yield than standard checks CORH 3 and Improved white ponni. Many scientists have advocated that two line hybrids have 510 per cent of yield advantage over three line hybrids can be released for cultivation, as three line hybrids have their own limitations. Breeders are looking for less complex and more efficient system of hybrid breeding which will attract large scale adoption of the technology by the farmers. Since two line hybrids have many advantages, the hybrids with on par performance to three line hybrids could also be recommended for commercial cultivation.

\section{REFERENCES}

Akter, S., Biswas, B.K. Azad, A.K. Hasanuzzaman, M. and Arifuzzaman, M. (2010). Correlation and discriminant function analysis of some selected characters in fine Rice (Oryza sativa L.) available in Bangladesh. International Journal of Sustainable Crop Production 5(4): 3035.

Arasakesary, S.J., Manonmani, S. Pushpam, R. and Robin, S. (2015). New temperature sensitive genic male sterile lines with better out crossing ability for production of two-line hybrid rice. Rice Science 22(1): 49-52.

Dhillion, B.S. (1975). The application of partial diallel crosses in plant breeding - A review. Crop Improvement 2: 1 $-7$.

Dhivyapriya, D. and Kalaiyarasi, R. (2014).Combining ability of TGMS lines and utilization of heterosis in rice (Oryza sativa L.). Trends in biosciences 7(19): 30643071.

Dhivyapriya, D., Karpagam, V. and Kalaiyarasi, R. (2015). Morphological characterization of thermo sensitive genic male sterile lines for floral traits in Rice. Annals of Plant and Soil Research 17 (Special Issue): 286-289.

Fonseca, S. and Patterson, F.L. (1968). Hybrid vigour in seven parent diallel cross in common wheat (Triticum aestivum L.). Crop Science 2: 85-88.

Gilbert, N.E.G. (1958). Diallel cross in plant breeding. Heredity 12: 477-498.

Gopikannan, M. and Ganesh, S. K. (2013). Investigation on combining ability and heterosis for sodicity tolerance in rice (Oryza sativa L.). African Journal of Agricultural Research 8(32): 4326-4333.

Hasan, M.J., Kulsum, U.K. Lipi L.F. and Shamsuddin, A.K.M. (2013). Combining ability studies for developing new rice hybrids in Bangladesh. Bangladesh Journal of Botany 42(2): 215-222.

Kalitha, U.C. and Upadhaya, L.P. (2000). Line x Tester anal- 
ysis of combining ability in rice under irrigated low land condition. Oryza 37: 15-19.

Kempthorne, O. (1957). An Introduction to Genetic Statistics. John Wiley and Sons, Inc., New York, pp. 399472.

Panse, V.G. and P.V. Sukhatme. (1964). Statistical Methods for Agricultural Research Workers, $2^{\text {nd }}$ Edition, ICAR, New Delhi.

Peng, J.Y. and Virmani, S.S. (1990). Combining ability for yield and four related traits in relation to breeding in rice. Oryza 27: 1-10.

Salgotra, R.K., Gupta, B.B. and Singh, P. (2009). Combining ability studies for yield and yield components in basmati rice. Oryza 46 (1): 12-16.

Sasikala, R., Kalaiyarasi, R. and Paramathama. M. (2015). Exploitation of two line heterosis utilizing thermosensitive genic male sterility sytem in rice. (Oryza sativa L.). International Journal of Tropical Agriculture 33(2): $1111-1117$.

Shivani, D., Viraktamath. B.C. and Shobha Rani, N. (2009).Combining ability for yield and grain quality characters in indica/indica hybrids of rice. Oryza 46(2):
152-155.

Singh, M., Ravi, K. Singh, P. and Singh. P. (2013). Identification of good combiners in early maturing $\times$ high yielding cultivars of indica rice (Oryza sativa L.). Bangladesh Journal of Botany 42(2): 247-255.

Snedecor, G.W. and W.G. Cochran. (1967). Statistical Methods. VI edition, Iowa state University press, Iowa, USA.

Stephen, R., Niya Celine, V.J. Manju, R.V. Shabana, R. Mohan, V. Nisthar, E. Anila , B.S. and Neethu, C. (2016). Marker assisted transfer of thermo sensitive genic male sterile gene to red rice (Oryza sativa L.) lines. International Journal of Tropical Agriculture (34) 5: $1251-1256$.

Utharasu, S. and C. R. Anandakumar. (2013). Heterosis and combining ability analysis for grain yield and its component traits in aerobic rice (Oryza sativa L.) cultivars. Electronic Journal of Plant Breeding 4(4): 1271- 1279.

Virmani, S.S. and Ilyas, M.A. (2001). Environment sensitive genic male sterility (EGMS) in crops. Advances in Agronomy 72: 139- 195.

Yuan, L. P. (1990). Progress of two line system hybrid rice breeding. Scientia Agicultura Sinica 3: 1-6. 